DOI: https://doi.org/10.24867/10CG02Varga

\title{
MATEMATIČKO MODELIRANJE BAČKOG DELA HIDROSISTEMA DTD PRIMENOM JEDNODIMENZIONALNOG MODELA HEC-RAS
}

\section{MATHEMATICAL MODELING OF THE BAČKA SECTION OF THE DANUBE-TISA- DANUBE CANAL USING A ONEDIMENSIONAL HEC-RAS MODEL}

\author{
Lilla Varga, Ljubomir Budinski, Fakultet tehničkih nauka, Novi Sad
}

\section{Oblast- GRAĐEVINARSTVO - HIDROTEHNIKA}

Kratak sadržaj - Tema ovog rada je matematičko modeliranje bačkog dela Hidrosistema Dunav-Tisa-Dunav pomoću softverskog paketa HEC-RAS. U radu su data detaljna objašnjenja načina unosa podataka potrebnih za kreiranje šematskog prikaza razmatranih kanalskih mreža, kao i testiranje verodostojnosti $i$ kvaliteta unetih podataka simuliranjem rada kanalske mreže.

Ključne reči: Matematičko modeliranje, Hidrosistem DTD, HEC-RAS

Abstract - The topic of this paper is the mathematical modeling of the Backa section of the Danube-TisaDanube Hydrosystem using the HEC-RAS software package. This paper provides a detailed explanation of the data entry methods needed to create a schematic representation of the considered channel networks, and the testing of the reliability and quality of the entered data by simulating the operation of the channel network.

Keywords: Mathematical modeling, Danube-TisaDanube Canal System, HEC-RAS

\section{UVOD}

Kao što je naš vrhunski vodoprivredni stručnjak inženjer Nikola Mirkov rekao, Vojvodini je priroda dala najplodniju zemlju u Evropi. Proučavajući i obilazeći obale reka i kanala, on je uočio da velike površine plodnog obradivog zemljišta dobrih svojstava i raspoložive količine vode, kao najznačajniji prirodni resursi i potencijali, čine da Vojvodina ima povoljne uslove za intenzivni razvoj i primenu navodnjavanja. Nikola Mirkov je još 1947. godine izložio ideju o gradnji hidrosistema Dunav-Tisa-Dunav. Koncept izgradnje je još te godine usvojen, i izrađen je i ,Osnovni projekat Velikog kanala DTD”. Radovi su započeti, međutim zbog političkih prilika prekinuti su na određeno vreme. 1952. godine posle dvogodišnje katastrofalne suše, Nikola Mirkov je ponovo pokrenuo akciju nastavka radova. Predlagao je da izgradnja Kanala DTD započne osposobljavanjem i iskorišćavanjem starih kanala $u$ Bačkoj. Tako je počela izgradnja polja za navodnjavanje duž postojećeg kanala Bezdan-Bečej. Izgradnja je trajala čitavih 20 godina,u njoj je učestvovalo 400 inženjera, urađeno je 1.300 elaborata na 135.000 kucanih strana $i$

\section{NAPOMENA:}

Ovaj rad proistekao je iz master rada, čiji mentor je bio prof. dr Ljubomir Budinski.
35.000 grafičkih crteža, ugrađeno je 500.000 kubnih metara betona i iskopano 130 miliona kubnih metara zemlje. Snimljeno je 1.7 miliona hektara teritorije Vojvodine, što je značilo i stvaranje novih karata regija Bačke i Banata [1].

\section{OSNOVNI PODACI O PODRUČJU}

Kanal Dunav-Tisa-Dunav predstavlja jedinstven sistem kanala između dve reke, Dunava i Tise, i kortisti se kao plovni put, ima veliku ulogu u odbrani protiv eventualnih poplava i neprocenjiva je njegova vrednost sa stanovištva navodnjavanja i odvodnjavanja poljoprivrednog zemljišta i prihvatanja otpadnih voda, a takođe treba istaći njegov značaj u u turizmu, lovu i ribolovu. Prostire se na teritoriji Vojvodine, u Bački i Banatu.

Ukupna dužina kanalske mreže iznosi približno 947 km. Na njoj postoje 24 kapije, 16 prevodnica, 5 sigurnosnih kapija, 6 pumpi i 180 mostova. Kanal je plovan na dužini od $664 \mathrm{~km}$. U sistemu se nalazi i 14 luka [2].

Podeljen je na dva dela: bački i banatski deo.

Bački deo se sastoji od 9 deonica:

- Bečej-Bogojevo,

- Vrbas-Bezdan,

- Novi Sad-Savino Selo,

- Bajski kanal,

- Odžaci-Sombor,

- Bački Petrovac-Karavukovo,

- Prigrevica-Bezdan,

- Kosančić-Mali Stapar,

- Jegrička.

Ukupna dužina bačkog dela iznosi $435,4 \mathrm{~km}$ i od toga je plovan na dužini od $370,1 \mathrm{~km}$.

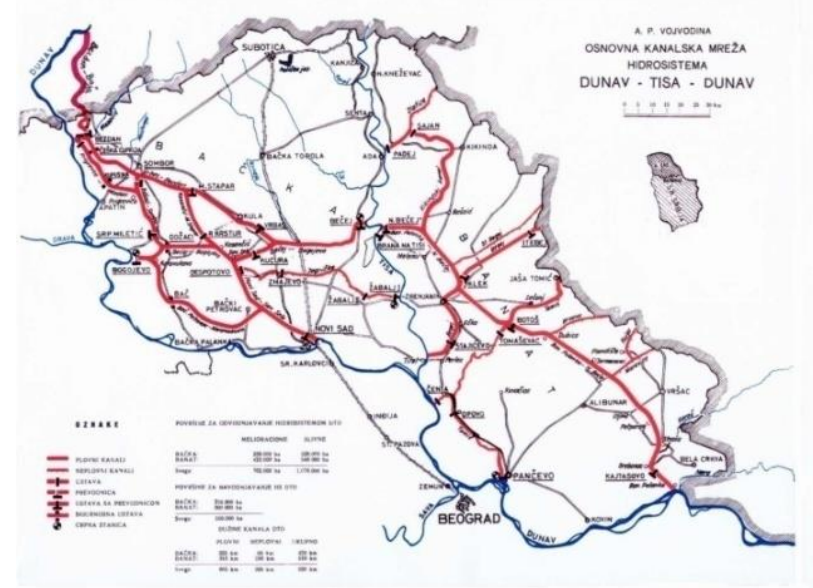

Slika 1. Prikaz Hidrosistema DTD 


\section{SOFTVERSKI PAKET HEC-RAS}

\subsection{O softverskom paketu HEC-RAS}

Programska aplikacija HEC-RAS predstavlja integrisani softver za modeliranje linijskog (jednodimenzionalnog) tečenja $u$ otvorenim tokovima sa mogućnošću modeliranja: ustaljenog i neustaljenog tečenja $u$ otvorenim tokovima proizvoljne geometrije proračuna pronosa nanosnih sedimenata i deformacije rečnog korita kao posledice kretanja tog nanosa, kao i rešavanje linijskog transporta potencijalnih zagađenja. Aplikacija takođe omogućuje da se na veoma jednostavan način modelira veliki broj lokalnih objekata kao što su mostovi, lokalna suženja i proširenja, brane, itd., i da na veoma kvalitetan način vizuelno i numerički prikaže i isprati svaki zahtev modeliranog slučaja. HEC-RAS je sveobuhvatni numerički softver koji daje kvalitetne i pouzdane rezultate modeliranja i kod najzahtevnijih hidrauličkih uslova nametnutih od strane prirodnih vodotokova [3].

Paket HEC-RAS je danas u velikoj meri zastupljen u inženjerskoj praksi kao osnovni alat za rešavanje i analizu velikog spektra hidrauličkih problema. Zauzima vodeće mesto među programima za jednodimenzionalno numeričko modeliranje strujanja u otvorenim tokovima. U nastavku će se detaljnije obraditi segment ustaljenog nejednolikog tečenja u otvorenim tokovima [3].

Modeliranje se sastoji od 5 koraka:

- Startovanja novog projekta,

- Unosa geometrije rečnog korita,

- Unosa ulaznih podataka i graničnih uslova za proračun,

- Izvršenja proračuna,

- Pregleda rezultata [4].

Za ovaj rad primenjen je programski paket HEC-RAS verzija 5.0.7.,slika 2.

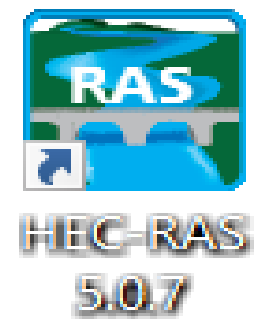

Slika 2 - HEC-RAS ikona na desktopu

\subsection{Primena programskog paketa HEC-RAS}

Rad u HEC-RAS-u je ogranizovan u "projektima" (datoteke sa nastavkom *.PRJ), koji u sebi sadrži sve podatke neophodne za proračun. Projektom su obuhvaćeni ulazni podaci i rezultati proračuna, $u$ tabelarnom i/ili grafičkom obliku. Za svaki projekat se otvara poseban radni direktorijum. Preporuka je da se sve datoteke jednog projekta drže $\mathrm{u}$ istom direktorijumu.

Ulazni podaci obuhvataju:

- Geometrijske podatke, koji se sastoje od šematskog prikaza vodotoka i njegovih pritoka ("River Systen Shematic"), podatke o poprečnim profilima i objektima, kao što su mostovi, pripusti, ustave, prelivi, brane itd hrapavosti korita (Maningov koeficijent). Ovi podaci se čuvaju u datotekama sa nastavkom *.Gbb ("bb" označava broj datoteke sa geometrijskim podacima).
- Podatke o protocima i graničnim uslovima, koje se čuvaju u datotekama sa nastavkom *.Fbb ("bb" označava broj datotoke sa navedenim podacima).

Rezultati proračuna nalaze se $\mathrm{u}$ datotekama sa nastavkom

*.Rbb, dok grafički ili tabelarni prikazi su označeni sa *.Obb [5].

Na slici 3 je prikazan osnovni prozor HEC-RAS softvera sa svim komandama.

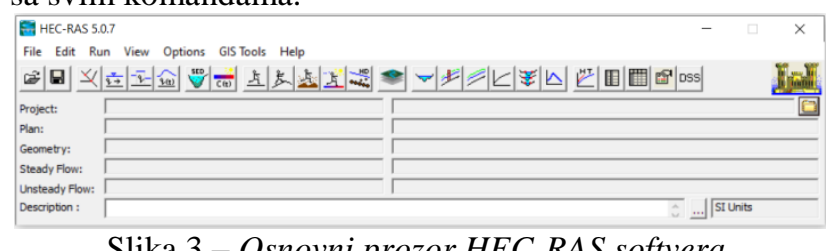

Slika 3 - Osnovni prozor HEC-RAS softvera

Prvi korak je unos ulaznih, tj geometrijskih podataka. Ove podatke čine podaci o trasi vodotoka sa pritokama, podaci o poprečnim profilima, objektima (mostovi, propusti, prelivi itd.), podaci o hrapavosti korita (vrednosti Maningovog koeficijenta).

Sledeći korak je unos podataka rečnih deonica. Ovaj korak se može realizovati na više načina. Jedan način jeste ručno crtanje rečnih deonica. Po završetku crtanja, dobija se šematski prikaz trase vodotoka sa položajem poprečnih profila.

Drugi način podrazumeva da se koordinatne vrednosti unesu iz spoljnih fajlova, kao npr. iz MS Excel ili GIS file-a. Prilikom matematičkog modeliranja koristiće se CSV ("Comma Separated Value") forma za unos geometrijskih podataka. U programski paket HEC-RAS moguće je ubaciti poprečne profile u formi X-Y-Z tako što se pomoću Excel programa formira tabela sa poljima RIVER_NAME, RIVER_REACH, RIVER_STATION, $\mathrm{X}, \mathrm{Y}, \mathrm{Z}$, kao što je prikazano u slici 4.

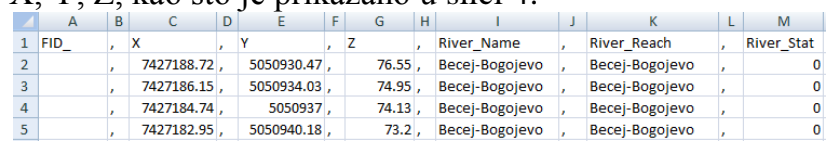

Slika 4 - Izgled CVS forme

Nakon završetka crtanja šematkog prikaza vodotoka sa položajem računskih poprečnih profila, prelazi se na učitvanje geometrije tih profila sa komandom "Cross section". Kad otvorimo editor dobijemo preglednu tabelu sa svim karakteristikama pojedinačnih profila. Za svaki profil treba definisati odstojanje do sledećeg profila "Downstream Reach Lengths", koordinate tačaka "Station" i "Elevation" i Manning-ov koeficijent "Maninng's n Values".

Deonice se spajanju pomoću komande Junctions. Čvorovi deonica su definisani kao lokacije na kojima se spajaju ili razdvajaju dva ili više protoka. Podaci spajanja sastoje se od opisa: rastojanje deonica na kojoj se spajaju ili razdvajaju, pritočni uglovi spajanja ili razdvajanja, modeliranje pristupa.

Hidrotehnički objekti koje se nalaze na Hidrosistemu DTD, prelivi i ustave, modelirani su pomoću komande "Inline Structure" iz prozora "Geometric Data".

Pokretanjem iz glavnog menija "Edit/Steady Flow Data" ili pritiskom na četvrtu ikonu s leva otvara se prozor sa podacima o protocima i odgovarajućim graničnim uslovima. Dobijeni rezultati mogu se prikazati u grafičkom ili tabelarnom obliku i nalaze se u glavnom meniju. 


\section{ANALIZA PODATAKA}

Analiza podataka se sastoji iz dva dela:

U prvom delu analize formiran je bački deo Hidrosistema DTD sa svim potrebnim karakteristikama poprečnih preseka, hidrotehničkim objektima i graničnim uslovima za proračun i izvršena simulacija test modela radi provere verodostojnosti i kvaliteta unetih podataka rada kanalske mreže.

U drugom delu analize na jednom delu kanalske mreže se vrši simulacija transporta zagađenja i analizira se ponašanje modela tokom simulacije.

\subsection{Formiranje kanalske mreže i puštanje test modela}

Cilj ovog dela rada je da u softverskom paketu HEC-RAS formira kanalska mreža uz puštanje nekog protoka samo do te mere da se testira verodostojnost i kvalitet unetih podataka.

Kanalska mreža je podeljena na 8 deonica, ukupne dužine 390.8 km i sadrži ukupno 4055 poprečnih preseka. Prosečna razdaljina između poprečnih profila je oko $100 \mathrm{~m}$. U tabeli 1. prikazani su karaktersitike deonica kanalske mreže:

Tabela 1. Tabela sa deonicama kanalske mreže

\begin{tabular}{|c|c|c|c|}
\hline & $\begin{array}{c}\text { Dužina } \\
\text { pojedinih } \\
\text { deonica } \\
{[\mathrm{km}]}\end{array}$ & $\begin{array}{c}\text { Broj } \\
\text { poprečnih } \\
\text { profila }\end{array}$ & $\begin{array}{c}\text { Prosečna } \\
\text { razdaljina } \\
\text { između } \\
\text { poprečnih } \\
\text { profila [m] }\end{array}$ \\
\hline $\begin{array}{c}\text { Bečej - } \\
\text { Bogojevo }\end{array}$ & 90 & 903 & 99.96 \\
\hline Vrbas - Bezdan & 80.9 & 857 & 94.99 \\
\hline $\begin{array}{c}\text { Novi Sad - } \\
\text { Savino Selo }\end{array}$ & 39.1 & 382 & 100.97 \\
\hline $\begin{array}{c}\text { Odžaci - } \\
\text { Sombor }\end{array}$ & 10.6 & 269 & 102.50 \\
\hline $\begin{array}{c}\text { Bački Petrovac } \\
\text { Karavukovo }\end{array}$ & 52.1 & 517 & 99.80 \\
\hline $\begin{array}{c}\text { Prigrevica - } \\
\text { Bezdan }\end{array}$ & 31.7 & 317 & 97.98 \\
\hline $\begin{array}{c}\text { Kosančić - } \\
\text { Mali Stapar }\end{array}$ & 21.1 & 207 & 100.65 \\
\hline Jegrička & 65.3 & 603 & 105.88 \\
\hline Ukupno & $\mathbf{3 9 0 . 8}$ & $\mathbf{4 0 5 5}$ & $\mathbf{1 0 0 . 3 4}$ \\
\hline
\end{tabular}

Deonice se spajaju na mestima:

- Čvor Prigrevica spaja deonicu Prigrevica - Bezdan i Odžaci - Sombor,

- Čvor Odžaci spaja deonicu Odžaci - Sombor i Bečej Bogojevo,

- Čvor Vrbas spaja deonicu Bečej - Bogojevo i Vrbas Bezdan,

- Čvor Kosančić sapja deonicu Bečej - Bogojevo i Kosančić - Mali Stapar,

- Čvor Bački Petrovac spaja deonicu Novi Sad - Savino Selo i Bački Petrovac - Karavukovo.

A razdvajaju u čvorovima:

- Čvor Sombor razdvaja deonicu Vrbas - Bezdan i Odžaci - Sombor,

- Čvor Mali Stapar razdvaja deonicu Vrbas - Bezdan i Kosančić - Mali Stapar,

- Čvor Karavukovo razdvaja deonicu Bečej - Bogojevo i Bački Petrovac - Karavukovo,
- Čvor Savino Selo razdvaja deonicu Bečej - Bogojevo i Novi Sad - Savino Selo,

- Čvor Despotovo razdvaja deonicu Novi Sad - Savino Selo i Jegrička.

U šemu kanalske mreže uneti su hidrotehnički objekti: ustava Bečej, ustava Novi Sad, ustava Bezdan, ustava Kucura, ustava Ruski Krstur, ustava Despotovo, ustava Mali Stapar, ustava Srpski Miletić, ustava Vrbas, ustava Žabalj, sigurnosna ustava Češka Ćuprija, sigurnosna ustava Kupusina, sigurnosna ustava Bač, sigurnosna ustava Odžaci i preliv Zmajevo[6].

Podaci o kanalskoj mreži dobijeni su od strane JVP "Vode Vojvodine" i nalaze se u Pravilniku o održavanju vodnog režima na hidrosistemu Dunav-Tisa-Dunav deo I-1 (Bački deo hidrosistema). Podaci sa poprečnim profilima su dobijeni u MS Excel formatu. Svaki poprečni profil sadrži u proseku između 20-50 tačaka sa izmerenim $\mathrm{X}, \mathrm{Y}$ i Z kotama i stacionažama, koji su pretovreni $\mathrm{u}$ .CVS fajl.

Zbog nedostatka merenih podataka na kanalskoj mreži, tj. protoka i kota nivoa vode, izvršiće se proračun sa proizvoljnim graničnim uslovima. Softverski paket HECRAS računa svaku deonicu pojedinačno, zbog toga svakoj deonici treba odrediti granične uslove.

Granični uslovi predstavljaju kote nivoa vode na najnizvodnijim profilima za sve računske protoke.

$\mathrm{Na}$ slici 5 se vidi šematski prikaz cele kanalske mreže u softveru HEC-RAS.

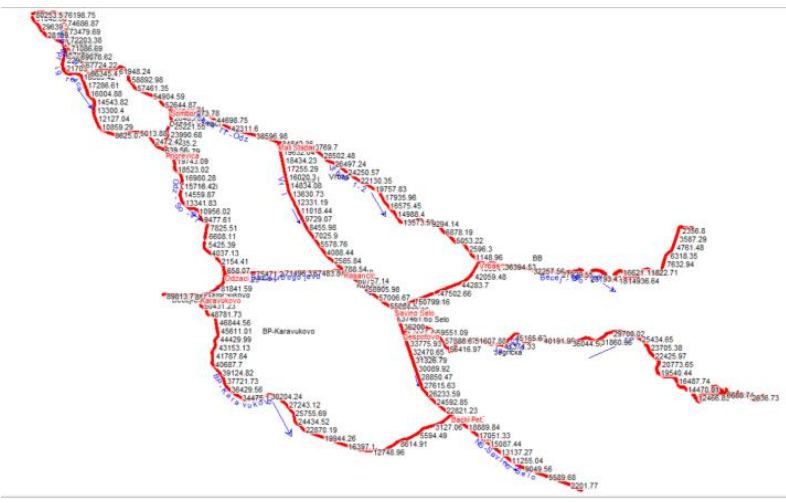

Slika 5. Šematski prikaz kanalske mreže

\subsection{Simuliranje transporta zagađenja}

Trećeg novembra 2019. godine u Srbobranu na delu Hidrosistema DTD pojavio se novi pomor ribe. Uz samu obalu voda je izbacila velike količine uginule ribe, dok je istovremeno ona koja je još bila živa pokušavala izlaskom na površinu da dođe do vazduha. Stradala je riba u delu vodotoka između Vrbasa i Turije, dok je u najširem delu u Srbobranu pomor najprimetniji. Na obali se mogu pronaći primerci svih vrsta ribe, od mlađi pa sve do kapitalaca. Prema saopštenju nadležnih za zaštitu životne sredine u Kuli 19. novembra 2019., za ovu ekološku katastrofu odgovoran krivac je šećerana u Crvenki, koja je u vodu ispustila hemikalije zbog kojih izumire biljni i životinjksi svet u kanalu[7].

Uz podatke koje su nam dostavljeni od strane JVP "Vode Vojvodine" simuliraće se transport zagađenja na deonici kanala Vrbas-Bezdan, od Vrbasa do Crvenke i na deonici kanala Bečej-Bogojevo, od Bečeja do Kucure.

Za unos potrebnih podataka za proračun koristiće se komanda "Water Quality Data". 


\section{ZAKLJUČAK}

Tema ovog rada je matematičko modeliranje bačkog dela Hidrosistema Dunav-Tisa-Dunav pomoću softverskog paketa HEC-RAS. U radu su data detaljna objašnjenja načina unosa podataka potrebnih za kreiranje šematskog prikaza razmatranih kanalskih mreža, kao i način testiranja verodostojnosti i kvaliteta unetih podataka simuliranjem rada kanalske mreže.

Razmatrana su dva slučaja simuliranja rada kanalske mreže i zaključuje se sledeće:

Prvi slučaj je simulacija rada cele kanalske mreže sa proizvoljnim graničnim uslovima. Zaključuje se da je matematički model stabilan i kvalitet unošenih podataka verodostojan. Na svakoj deonici su zadovoljeni osnovni principi održavanja vodnog režima kanalske mreže.što znači da je matematički model primenljiv i za zvanične vrednosti graničnih uslova, koji bi se dobijali merenjem kota nivoa i praćenjem protoka vode od strane zaduženih službi. U tu svrhu bi trebalo izgraditi i postaviti instalaciju merne opreme za svaku deonicu kanalske mreže. Očitavanjem i sistematizacijom izmerenih podataka zajedno sa ovim softverom bi se napravio sistem za manipulaciju, monitorting i upravljanje radom kanalske mreže.

Drugi slučaj je simuliranje transporta zagađenja na kanalu Vrbas - Bezdan, na deonici Vrbas - Crvenka i na kanalu Bečej - Bogojevo, na deonici Bečej - Kucura. Zaključuje se da je model stabilan i da se može pouzdano koristiti za simulaciju transporta zagađenja.

\section{LITERATURA}

[1] https://www.dotkomsite.com/price-iz-ravnice/nikolamirkov-tvorac-dtd-kanala-vojvodanskog-krvotoka/

[2] Univerzitet u Novom Sadu Fakultet tehničkih nauka, JVP "Vode Vojvodine" Novi Sad, "Hidroinvest DTD" AD Novi Sad, Pravilnik o odrlavanju vodnog režima na hidrosistemu Dunav-Tisa-Dunav deo I-1 (Bački deo hidrosistema)

[3] Budinski Ljubomir, Slajdovi za predavanje Ustaljeno nejednoliko tečenje u kanalima -programski paket HEC-RAS

[4] HEC-RAS River Analysis System User's Manual

[5] Đorđević Dejana, Rosić Nikola i Jovanović Miodrag, diplomski rad HEC-RAS - Korisničko uputsvo

[6] Univerzitet u Novom Sadu Fakultet tehničkih nauka, JVP "Vode Vojvodine" Novi Sad, "Hidroinvest DTD" AD Novi Sad, Pravilnik o odrlavanju vodnog režima na hidrosistemu Dunav-Tisa-Dunav deo I-1 (Bački deo hidrosistema)

[7] https://srbobrandanas.rs/2019/11/03/novi-pomor-ribeu-kanalu-dtd

\section{Kratka biografija:}

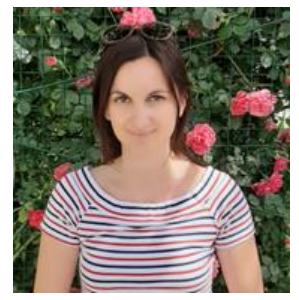

Lilla Varga rođena je u Senti 1991. godine. Diplomski rad iz oblasti građevinarstvo, na temu „Projekat sistema za navodnjavanje BEČEJ II“, odbranila je 2017. godine na Fakultetu tehničkih nauka u Novom Sadu. Trenutno student master studija istog fakulteta - smer Hidrotehnika.

Ljubomir Budinski rođen je u Kuli 1976. godine. Doktorsku disertaciju odbranio je na Građevinskom fakultetu u Subotici. Od 2011. godine ima zvanje docenta. 